\title{
Thermal characteristics and analysis of pyrolysis effects during the mechanical alloying process of Astaloy CrM powders
}

\author{
Marek Hebda $\cdot$ Szymon Gądek · Jan Kazior
}

$3^{\text {rd }}$ Joint Czech-Hungarian-Polish-Slovak Thermoanalytical Conference Special Chapter

(C) The Author(s) 2012. This article is published with open access at Springerlink.com

\begin{abstract}
Mechanical alloying processes are carried out usually with addition of some lubricants, referred to also as a process control agents (PCA). About $1-2 \mathrm{wt} \%$ of a PCA (usually stearic acid) is normally added to prevent excessive cold welding amongst the powder particles, especially when powders of ductile metals are milled. However, lubricants (maybe disintegrated after MA process) must be removed in the early stages of heating during the sintering process. The aim of the present study was to determine the effect of the MA process especially (i) milling time and (ii) influence of lubricant addition on thermal effects during heating of iron powder (Astaloy $\mathrm{CrM}$ ) with the addition of $1 \mathrm{wt} \%$ stearic acid measured by differential scanning calorimeter (DSC) and thermogravimetry (TG) techniques. Removal of the lubricants during heating of the blended powders and exhaust gases from the furnace were monitored by quadruple mass spectrometry (QMS). Determination of the physical and technological properties of the powder mixture obtained from MA was performed with a laser particle sizer. Distribution of particle sizes, flow and apparent density were also measured. Furthermore, the shape and morphology of the powders were characterised by a light optical microscope (LOM) and scanning electron microscope (SEM).
\end{abstract}

Keywords Mechanical alloying - Stearic acid . Gas analyses · Pyrolysis

M. Hebda $(\bowtie) \cdot$ S. Gądek · J. Kazior

Institute of Material Engineering, Cracow University of Technology, ul. Warszawska 24, 31-155 Krakow, Poland e-mail: mhebda@pk.edu.pl

\section{Introduction}

The mechanical alloying (MA) process, using ball- and/or rod-milling techniques, has received much attention as a powerful tool for the fabrication of several advanced materials, including equilibrium, nonequilibrium (e.g. amorphous, quasicrystals, nanocrystalline, etc.) and composite materials. Consequently, it can be used to produce alloys and compounds that are difficult or impossible to obtain via conventional melting and casting techniques $[1,2]$. However, the 'science' of MA has been investigated only during the past 20 years or so. The technique of mechanochemistry, on the other hand, has had a long history (since pioneer work by Benjamin in the early 1960s) and the materials produced in this way have found a number of technological applications. In contrast, the technique of MA was used for industrial applications from the beginning but the basic understanding and mechanism of the process is beginning to be understood only now [3].

Lubricants have become essential in powder metallurgy (PM) parts production. They are typically admixed $(0.5-1.5 \mathrm{wt} \%)$ with the metal powder to aid compaction uniformity and to decrease die-wall friction during compaction and ejection, thereby reducing die wear. Lubricants can also act as temporary binders to enhance the 'green' strength of a metal part. However, the lubricant remaining on and within the compact may restrict densification during sintering and, therefore, it must be removed in the early stages of heating [4]. In the MA process, lubricants can also act as a process control agent (PCA) to prevent the alloying of the powder before its coagulation to prevent excessive cold welding $[5,6]$.

The aim of this article was to present the results of research focused on Astaloy CrM powder properties after both (i) the MA process with different numbers of alloying cycles and (ii) stearic acid addition. 
For a better understanding of the resulting phenomena (thermal behaviour and pyrolysis effects) during MA, we used coupled thermal analysing equipment (DSC/TG/ QMS). Furthermore, shape morphology (by SEM and LOM), particle size distribution (using laser particle sizing) and microhardness of the powders were also characterised.

\section{Experimental}

Material

The specimens were prepared by the mechanical alloying of Astaloy CrM powders (water atomised iron powder with the addition of $3.0 \% \mathrm{Cr}$ and $0.5 \%$ Mo manufactured and supplied by Höganäs) with $1 \mathrm{wt} \%$ stearic acid (supplied by Sigma-Aldrich). Stearic acid $\left(\mathrm{CH}_{3}\left(\mathrm{CH}_{2}\right)_{16} \mathrm{COOH}\right)$ was added to the powder mixture as the agent with the aim of controlling the mechanical alloying process and, in principle, to avoid powder particle agglomeration. The total mass of alloyed mixture was about $80 \mathrm{~g}$.

\section{Methods}

\section{Mechanical alloying}

For MA, a highly energetic planetary mono ball mill (Fritsch, Pulverissette 6 model) was used. The process was carried out in a tempered steel container $(500 \mathrm{~mL}$ volume) equipped with grinding balls (ball bearing steel AISI $52100)$ of diameter $\varnothing 10 \mathrm{~mm}$ in a vacuo. The ratio of powder mass to ball mass was at a level of 1:10. The milling time was $3 \mathrm{~min}$, intermission period $30 \mathrm{~min}$, the number of cycles 40 , rotary speed $500 \mathrm{rev} / \mathrm{min}$.

\section{Sampling}

To analyse the influence of milling time on the thermal behaviour of the investigated mixture powder, samples containing $5 \mathrm{~g}$ of powder and $50 \mathrm{~g}$ of milling balls were collected after 4 iterations (cycles) of milling to grain size to determine microhardness. In order to protect the powder samples against an oxidising atmosphere and pollution, a plexiglass chamber with an argon (5.0) atmosphere (gas flow about $100 \mathrm{~mL} / \mathrm{min}$ ) was used. A total of 10 different milling times (number of alloying cycles) were chosen as measurements (Table 1).

\section{Thermal analysis studies}

Thermal measurements were performed with STA 409 CD (Netzsch) advance coupling techniques (DSC/TG) including evolved gas analysis by Quadruple Mass Spectrometry
Table 1 Performed powder compounds with notation

\begin{tabular}{lll}
\hline $\begin{array}{l}\text { Notation corresponding } \\
\text { to number of mechanical } \\
\text { alloying cycles }\end{array}$ & $\begin{array}{l}\text { Milling } \\
\text { time/min }\end{array}$ & $\begin{array}{l}\text { Total time (milling } \\
\text { time }+ \text { intermission)/min }\end{array}$ \\
\hline 0 & 0 & 0 \\
4 & 12 & 33 \\
8 & 24 & 66 \\
12 & 36 & 99 \\
16 & 48 & 132 \\
20 & 60 & 165 \\
24 & 72 & 198 \\
28 & 84 & 231 \\
32 & 96 & 264 \\
36 & 108 & 297 \\
40 & 120 & 330 \\
\hline
\end{tabular}

(QMS 403/5 SKIMMER). Two replicates were measured. The calorimetric curves were recorded with a differential scanning calorimeter using a closed alumina crucible ( $85 \mu \mathrm{L}$, there was a $50 \mu \mathrm{m}$ hole in the lead), with about $150 \mathrm{mg}$ of samples under a dynamic argon (5.0) atmosphere $(80 \mathrm{~mL} / \mathrm{min})$. The temperature range was from 30 to $1,200{ }^{\circ} \mathrm{C}$ at a heating rate of $10 \mathrm{C} / \mathrm{min}$. An empty closed alumina crucible was used as a reference. The apparatus was calibrated using indium, tin, bismuth, zinc, aluminium, silver and gold as a standard. The heat flow signal was calibrated by the melting heat of the abovementioned elements. The on-line gas analysis (distance between the sample and QMS was less than $20 \mathrm{~mm}$ ) was studied by QMS with an electron ionisation source. The spectrometer was operated in MID (Multiple Ion Detection) mode. Argon (5.0) was used as a carrier gas at a flow rate of $80 \mathrm{~mL} / \mathrm{min}$. The QMS was checked using Calcium Oxalate Monohydrate (Fluka). The DSC/TG/QMS data were analysed using Proteus software (ver. 5.2.0) from Netzsch. All of presented curves were corrected against empty runs.

\section{Carbon determination}

Elemental analysis of carbon content was also performed on LECO CS-125 apparatus with detection by IR, following ASTM E 1019 standard.

\section{SEM, HV and particle size measurements}

A characterisation of the powder's shape and particle size was performed by a scanning electron microscope (SEM), model JEOL JSM 5510LV, on graphite pads.

LOM analysis and microhardness HV0,01 (model Nexus 423A with Nexus Inv-1, at least ten replicates were measured) were performed for the included powders at 

the Astaloy CrM powder recorded upon heating the samples up to $1,200{ }^{\circ} \mathrm{C}$
Fig. 1 DSC and TG curves of
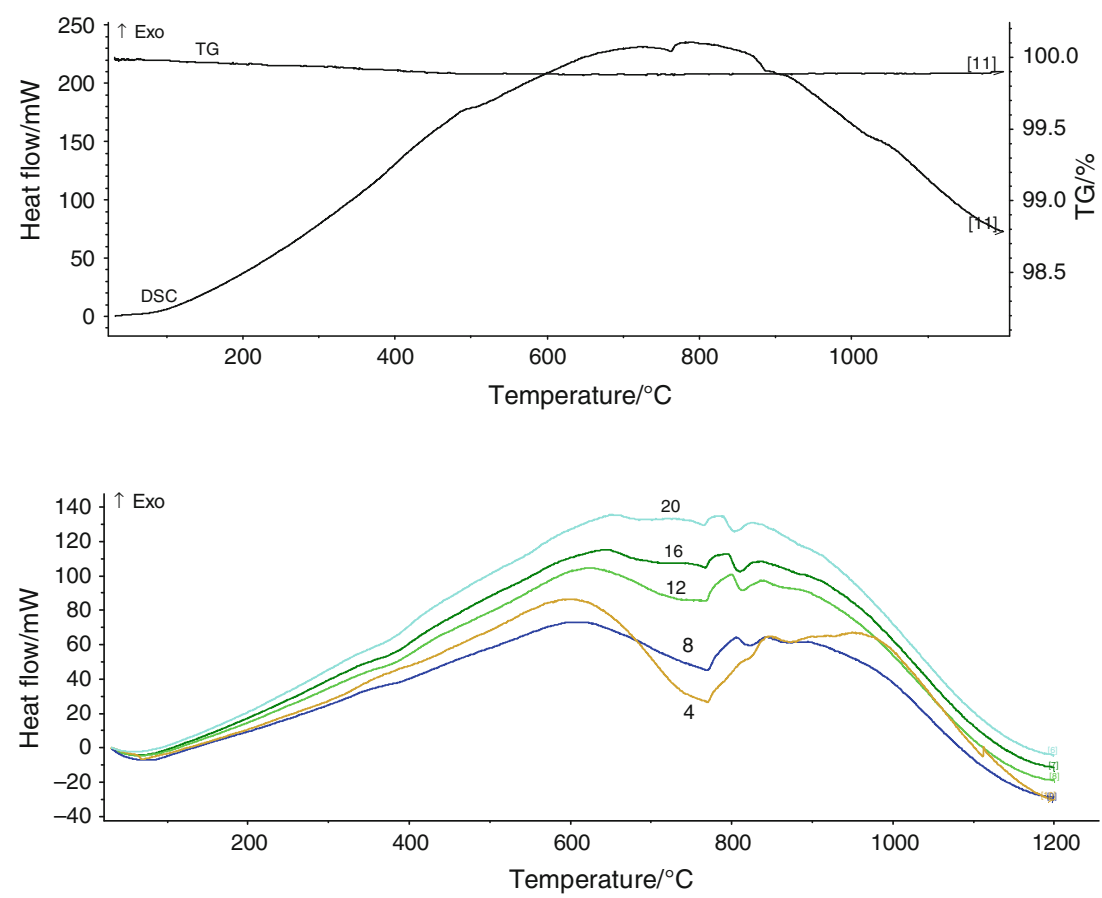

Fig. 2 DSC curves of the Astaloy CrM powder with the addition of $1 \mathrm{wt} \%$ stearic acid after 4 up to 20 mechanical alloying cycles (milling time) recorded upon heating the samples up to $1,200{ }^{\circ} \mathrm{C}$. (Color figure online)

Fig. 3 DSC curves of the Astaloy CrM powder with the addition of $1 \mathrm{wt} \%$ stearic acid after 24 up to 40 mechanical alloying cycles (milling time) recorded upon heating the samples up to $1,200{ }^{\circ} \mathrm{C}$. (Color figure online)

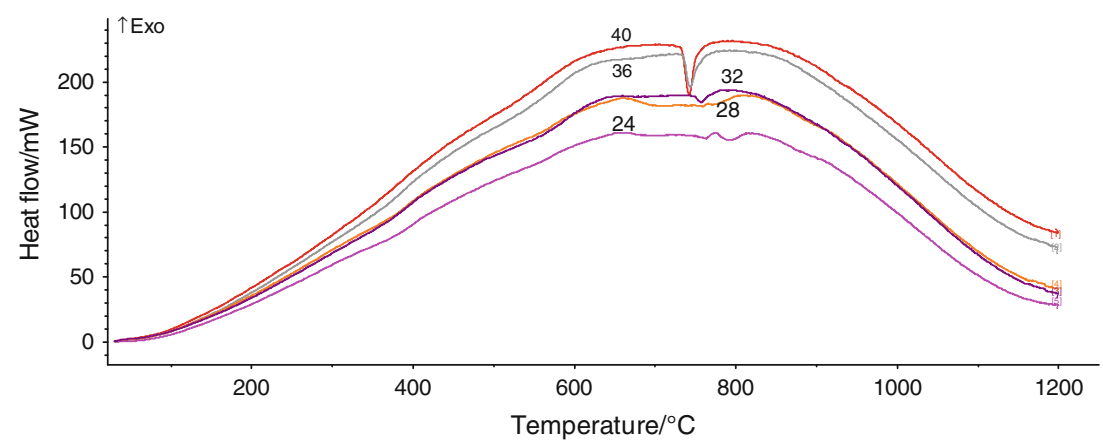

room temperature. Measurements of particle size were determined by laser particle sizer Analysette 22 MicroTec plus (Fritsch, five replicates were measured).

\section{Results and discussion}

Figure 1 presents the results of DSC and TG measurements of Astaloy CrM powder during heating. The DSC curves of Astaloy CrM powder showed two small endothermic peaks. The position of the first peak $\left(T_{\text {onset }} 715.5^{\circ} \mathrm{C}\right)$ corresponds to the Curie temperature, whilst the second peak $\left(T_{\text {onset }} 867.2^{\circ} \mathrm{C}\right)$ can be ascribed to the $\alpha \rightarrow \gamma$ transformation. On the other hand, the TG curve proved a flat, unchanged mass character during the whole thermal cycle.

The DSC curves for the Astaloy CrM with the addition of $1 \mathrm{wt} \%$ stearic acid obtained by mechanical alloying after different duration time are presented in Figs. 2 and 3.
The DSC traces showed significant changes in recorded curves as compared to the curves of the base powder. The samples collected at the beginning of the mechanical alloying process (after the 4th, 8th and 12th cycle of MA) were characterised by much more smeared out and intensive endothermic peaks occurring between 600 and $770{ }^{\circ} \mathrm{C}$ (Fig. 2). This effect was caused by the evaporation of the stearic acid, which was not alloyed with the powder samples. Increasing the milling time led to a decrease in all endothermic peak surfaces at $600-770{ }^{\circ} \mathrm{C}$. Furthermore, only for compositions obtained after the 4 th, 8th and 12th MA cycles were small endothermic peaks at a temperature around $850{ }^{\circ} \mathrm{C}$ detected (Tables 2, 3). This phenomenon can be probably correlated with the removal of lubricants from the furnace chamber. The removal of the lubricants cannot occur from the samples, because TG curve did not change after the 4th and 8th MA cycles in this temperature range (Fig. 4). Moreover, only for the specimen obtained after the 4th mechanical alloying cycle 
Table 2 Evolution of the $T_{\text {onset }}$ and $T_{\text {peak }}$ temperature of the recorded effects and changes of endothermic peak surface areas versus milling time

\begin{tabular}{|c|c|c|c|c|c|c|c|c|c|}
\hline \multirow[t]{2}{*}{ Notation } & \multicolumn{3}{|c|}{ First endothermic effect } & \multicolumn{3}{|c|}{ Second endothermic effect } & \multicolumn{3}{|c|}{ Third endothermic effect } \\
\hline & $T_{\text {onset }} /{ }^{\circ} \mathrm{C}$ & $T_{\text {peak }} /{ }^{\circ} \mathrm{C}$ & $\Delta H_{\text {exp }} / \mathrm{J} \mathrm{g} \mathrm{g}^{-1}$ & $T_{\text {onset }} /{ }^{\circ} \mathrm{C}$ & $T_{\text {peak }} /{ }^{\circ} \mathrm{C}$ & $\Delta H_{\text {exp }} / \mathrm{J} \mathrm{g}^{-1}$ & $T_{\text {onset }} /{ }^{\circ} \mathrm{C}$ & $T_{\text {peak }} /{ }^{\circ} \mathrm{C}$ & $\Delta H_{\exp } / \mathrm{J} \mathrm{g}^{-1}$ \\
\hline 0 & 715.5 & 762.6 & 5.2 & 867.2 & 887.4 & 5.3 & - & - & - \\
\hline 4 & 600.8 & 769.8 & 208.3 & 847.1 & 870.6 & 7.8 & 898.6 & 926.7 & 1.571 \\
\hline 8 & 612.3 & 770.2 & 74.2 & 806.4 & 812.8 & 3.8 & 842.3 & 864.8 & 2.243 \\
\hline 12 & 625.0 & 767.0 & 61.7 & 800.3 & 812.2 & 5.7 & 835.3 & 859.2 & 0.9828 \\
\hline 16 & 645.8 & 766.9 & 28.3 & 793.1 & 808.0 & 6.8 & - & - & - \\
\hline 20 & 654.3 & 764.9 & 11.3 & 787.5 & 802.6 & 5.9 & - & - & - \\
\hline 24 & 656.7 & 763.7 & 9.5 & 774.1 & 790.4 & 5.3 & - & - & - \\
\hline 28 & 661.7 & 759.2 & 10.8 & 765.2 & 770.7 & 1.8 & - & - & - \\
\hline 32 & 659.6 & 756.8 & 12.2 & - & - & - & - & - & - \\
\hline 36 & 727.1 & 742.6 & 16.0 & - & - & - & - & - & - \\
\hline 40 & 700.2 & 742.1 & 23.8 & - & - & - & - & - & - \\
\hline
\end{tabular}

Table 3 Evolution of the mass changes (\%) of the mechanical alloying compositions in three temperature ranges

\begin{tabular}{llll}
\hline Notation & \multicolumn{3}{l}{ Mass changes $/ \%$} \\
\cline { 2 - 4 } & $30-411 /{ }^{\circ} \mathrm{C}$ & $411-660 /{ }^{\circ} \mathrm{C}$ & $660-1200 /{ }^{\circ} \mathrm{C}$ \\
\hline 4 & -0.85 & -0.10 & - \\
8 & -0.63 & -0.22 & - \\
12 & -0.69 & -0.35 & -0.11 \\
16 & -0.56 & -0.44 & -0.06 \\
20 & -0.68 & -0.60 & -0.15 \\
24 & -0.53 & -0.70 & -0.17 \\
28 & -0.52 & -0.81 & -0.22 \\
32 & -0.36 & -0.89 & -0.22 \\
36 & -0.31 & -0.66 & -0.78 \\
40 & -0.06 & -0.57 & -0.85 \\
\hline
\end{tabular}

was there a small endothermic effect at $64^{\circ} \mathrm{C}$ corresponding to the melting of the added PCA recorded. When the milling time of the MA process increased, the high temperature endothermic effect (2nd and 3rd peaks-Table 2) constantly decreased and shifted to a lower temperature range, whilst the first peak moved to the higher temperature range. After 36 and 40 cycles of the MA process (108-120 min of milling time, respectively) magnetic transition at the Curie temperature during heating was detected, as well as the temperature of the $\alpha \rightarrow \gamma$ transformation, which overlapped. These phenomena were accompanied by a stronger endothermic peak. To summarise, all of the observed calorimetric effects can be explained in two ways: (i) as the influence of the mechanical alloying process of the analysed powders and (ii) as the effect of the applied lubricant.

Figure 5 presents the evolution of the microhardness HV0.01 of the investigated samples versus the amount of mechanical alloying cycles. It is clear that an increase in the microhardness of the investigated mixtures corresponds to the mechanical alloying process, in particular to the cold welding, fracturing and rewelding phenomena. During the first stage of milling of the Astaloy CrM powder (ductile particles), the cold welding processes will overcome the fracturing processes, thus leading to a large particle size. For longer milling times due to the cold hardening of the particles (Fig. 5), the balance between cold welding and fracturing is shifted to the fracturing processes, and the particle size decreases (Figs. 6, 7, 8).

Figure 5 shows that the microhardness of the mechanical alloying powder was stable up to 32 cycles of milling.
Fig. 4 TG trace of the Astaloy CrM powder with $1 \mathrm{wt} \%$ stearic acid addition: a after 4 up to 20 , b after 24 up to 40 mechanical alloying cycles (milling time) recorded upon heating the samples up to $1,200{ }^{\circ} \mathrm{C}$. (Color figure online)
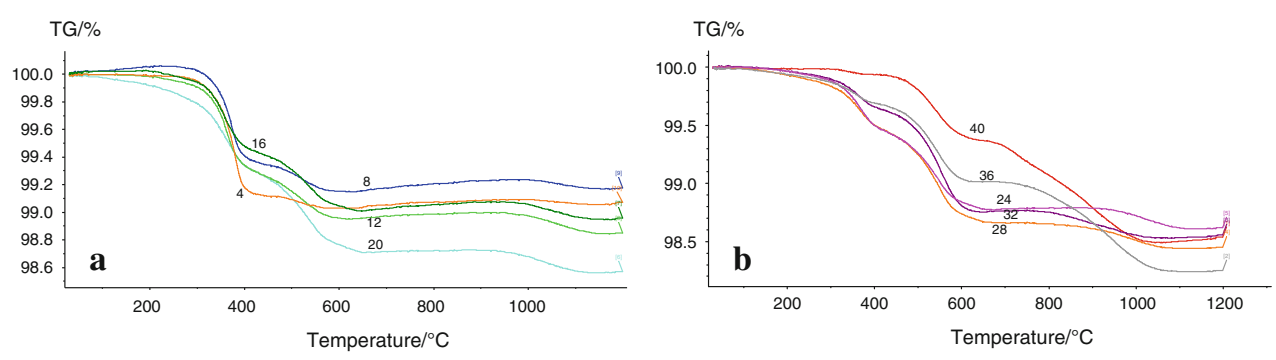


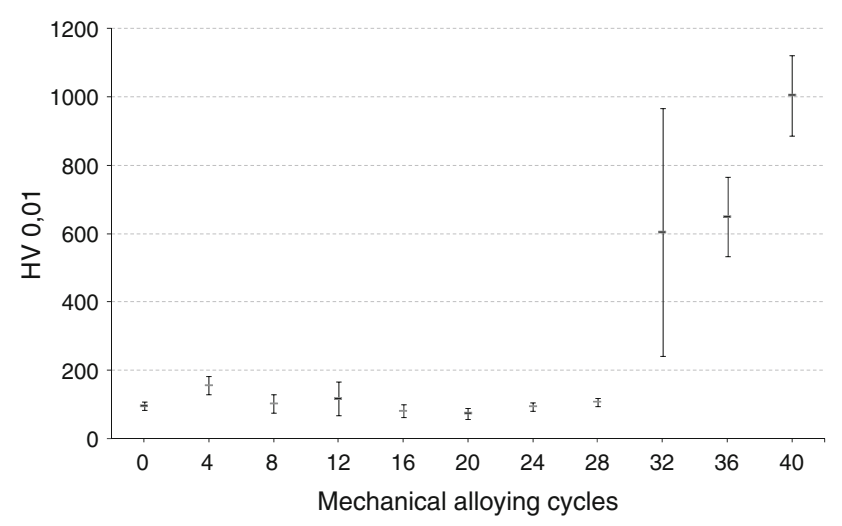

Fig. 5 Evolution of microhardness HV0.01 of the investigated samples versus the mechanical alloying cycles (milling time)

After that, increasing MA time caused significant increases of microhardness (about 5 times for samples after 32 and 36 cycles, and even 10 times after 40 cycles).
The sieve analysis was performed by wet particle distribution as shown in Fig. 8. The mean grain size for the based Astaloy CrM powder was located in the average range of $85 \mu \mathrm{m}$. After 20 cycles of MA, the particle size started to decrease (around $56 \mu \mathrm{m}$ ) and the measured peak was much wider in comparison to the non-alloyed powders. The longest milling time ( 40 cycles) resulted in $20 \%$ of particles with a size lower than $10 \mu \mathrm{m}$. The average value for this composition oscillated around $32 \mu \mathrm{m}$.

Moreover, the changes in particle size and morphology due to cold hardening had a strong influence on the apparent density (Fig. 9). At the beginning of the MA process, the apparent density decreased up to 32 cycles, and after that it started to increase.

Surface hardening and decrease in particle size are the main factors which are responsible for the disadvantages or limitations of powders prepared by the MA method. These factors disadvantage it in compaction with the classical
Fig. 6 Evolution of surface and shape morphology of the investigated samples versus the mechanical alloying cycles (milling time) analysed by LOM
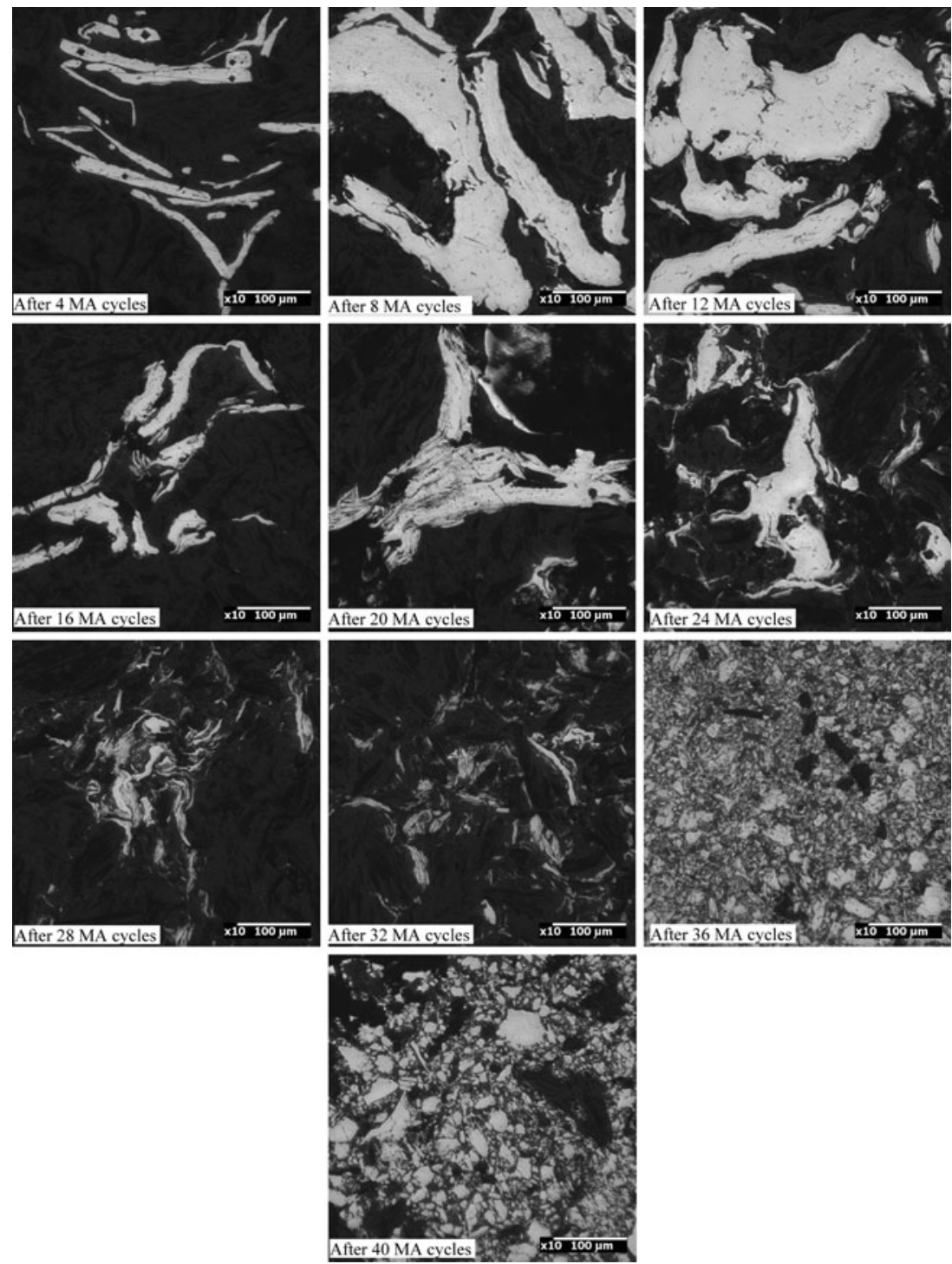
Fig. 7 Evolution of surface and shape morphology of the investigated samples versus the mechanical alloying cycles (milling time) analysed by SEM
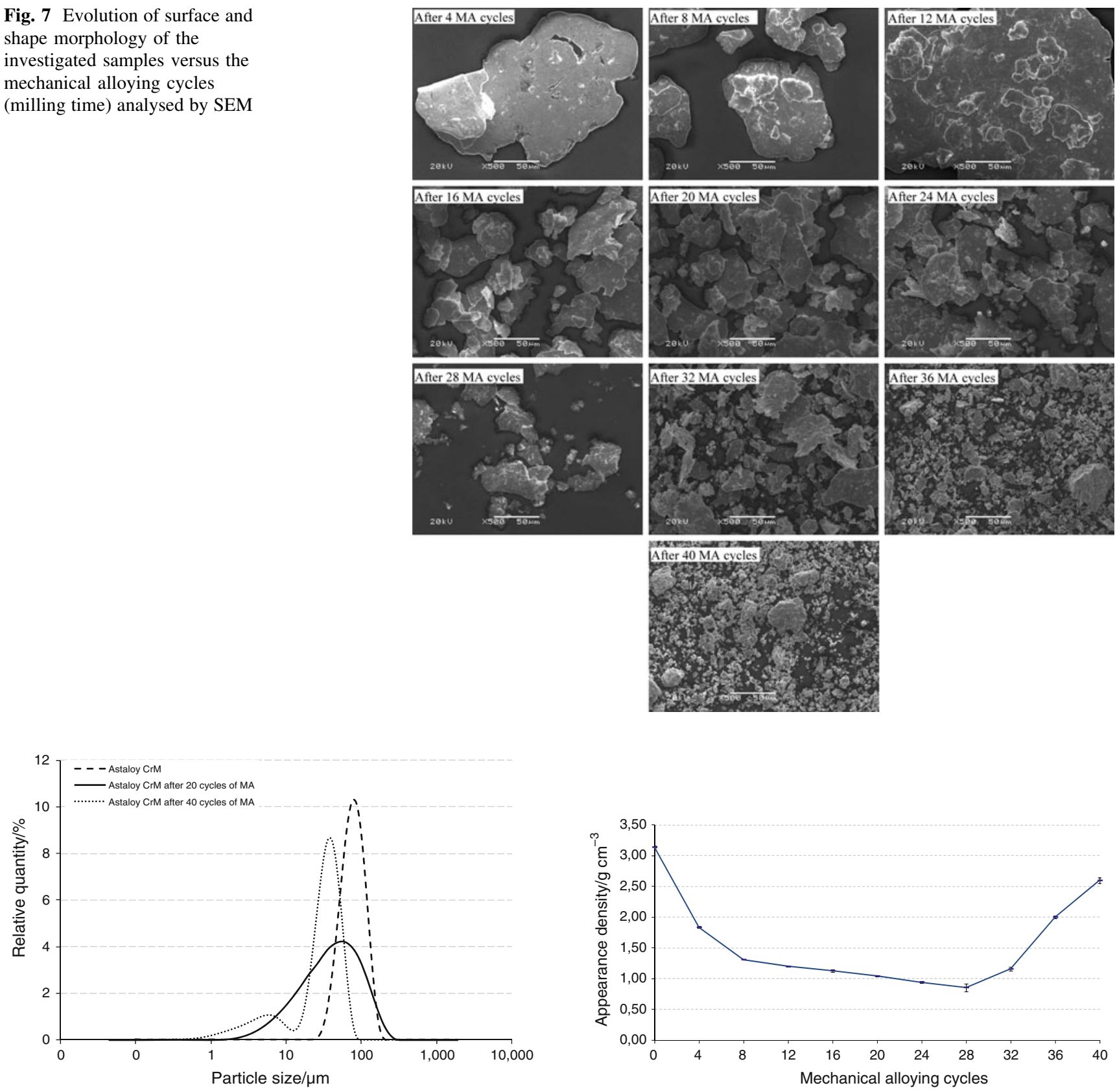

Fig. 8 Particle size distribution of base Astaloy CrM powder as well as after 20 and 40 cycles of the MA process

method of compaction. Therefore, Hot Isostatic Pressing (HIP), Selective Laser Sintering (SLS), Powder Injection Moulding (PIM) or Spark Plasma Sintering (SPS) are more efficient for powder pressing after the MA process.

The mass spectrometer allowed us to interpret the recorded TG traces (Fig. 4; Table 3). It could be concluded that during an increase in the milling time, stearic acid must be disintegrated (due to high ball energy and temperature). At the beginning of the MA process, up to 16 cycles, we observed similar TG traces with about $1 \%$ mass

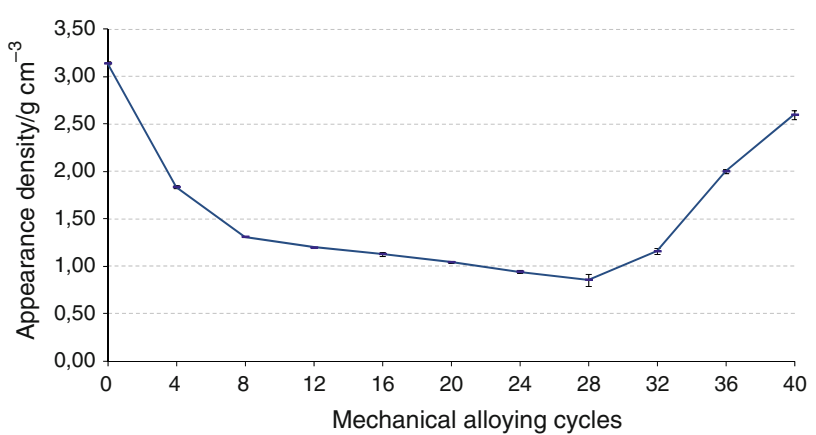

Fig. 9 Evolution of the apparent density of the investigated samples versus the amount of mechanical alloying cycles (milling time)

loss at the end of the measurements. From the mass spectrometry curves presented in Fig. 10, it was observed that the main products for these compositions were hydrocarbon products $(\mathrm{m} / \mathrm{z}, 29, \mathrm{~m} / \mathrm{z} 27, \mathrm{~m} / \mathrm{z} 26)$ and a methyl group $(\mathrm{m} / \mathrm{z}, 15)$, with intensity of signals $10 \mathrm{E}-11$. All the mass spectra decreased during the increase of mechanical alloying cycles (milling time). The gaseous products had three maxima of ion intensity: at about 400, 680 and $930{ }^{\circ} \mathrm{C}$. The first peak had a significant correlation with the recorded TG trace, whilst the second and third maxima 
Fig. 10 Mass spectra obtained via MID mode of the Astaloy CrM powder with $1 \mathrm{wt} \%$ stearic acid addition after mechanical alloying cycles recorded upon heating the samples up to

$1,200^{\circ} \mathrm{C}$. (Color figure online)

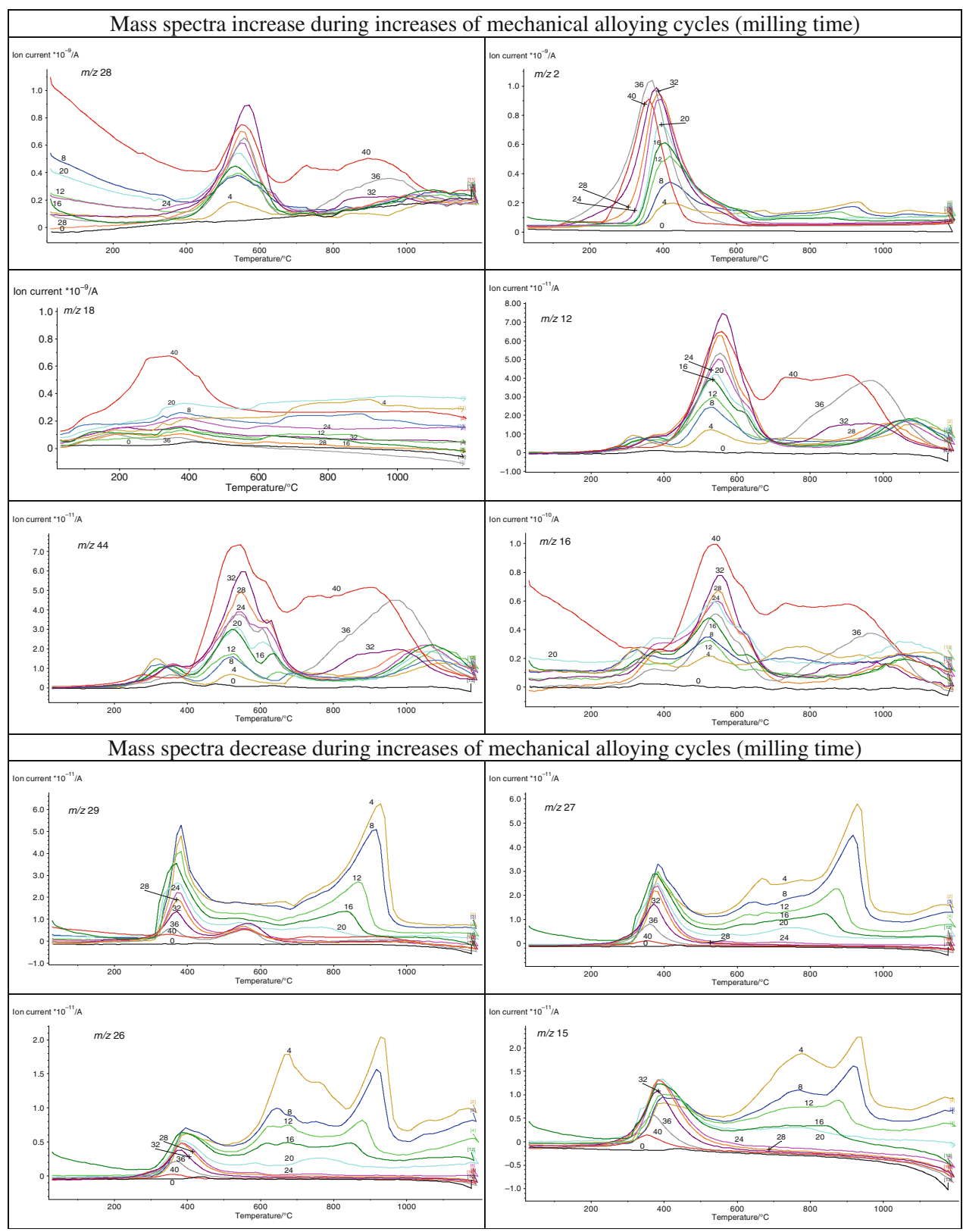

corresponded to the calorimetric effects observed on the DSC curves. When the milling time exceeded 16 cycles, we observed about $1.5 \%$ mass loss on the TG curves and changes in the recorded ion masses. This indicates that not only the direct disintegration of the lubricant affected the sintering process. It should be noticed that when the milling time was lengthened, a strong increase in hydrogen products $(\mathrm{m} / \mathrm{z}, 2)$ with a maximum peak at around $400{ }^{\circ} \mathrm{C}$ (as a result of the disintegration of the chemical chain of stearic acid by the MA process) was detected. For all investigated compositions, this gaseous product gave a high signal with intensity of $10 \mathrm{E}-9$. It suggests that, during longer milling time, the stearic acid in the samples must also be disintegrated, and helps in a reduction of the metallic oxides by the produced hydrogen. This explanation is strengthened by our observation that with milling time increase, a higher intensive signals from: (i) water $\left(\mathrm{H}_{2} \mathrm{O}\right.$-masses $\mathrm{m} / \mathrm{z} 18$, with maximum at about $\left.320^{\circ} \mathrm{C}\right)$ and (ii) carbon monoxide (CO-masses $\mathrm{m} / \mathrm{z} 28$ with maximum at about $560{ }^{\circ} \mathrm{C}$ ) was produced and gave an intensive signal comparable with $\mathrm{m} / \mathrm{z} 2$ (with intensity of $10 \mathrm{E}-9$ ). Moreover, Fig. 10 shows that at the same temperature as for $\mathrm{CO}$, signals from carbon dioxide $\left(\mathrm{CO}_{2}\right.$-mass $\mathrm{m} / \mathrm{z} 44$, $\mathrm{m} / \mathrm{z} 28, \mathrm{~m} / \mathrm{z} 16$ and $\mathrm{m} / \mathrm{z}, 12$ with intensity of $10 \mathrm{E}-11$ ) were also detected and increased with MA cycle increase. Specimens alloyed over 32 cycles showed a reduction of metallic oxides, also at a higher temperature range between 700 and $1,000{ }^{\circ} \mathrm{C}$ due to carbothermal reduction (presences 


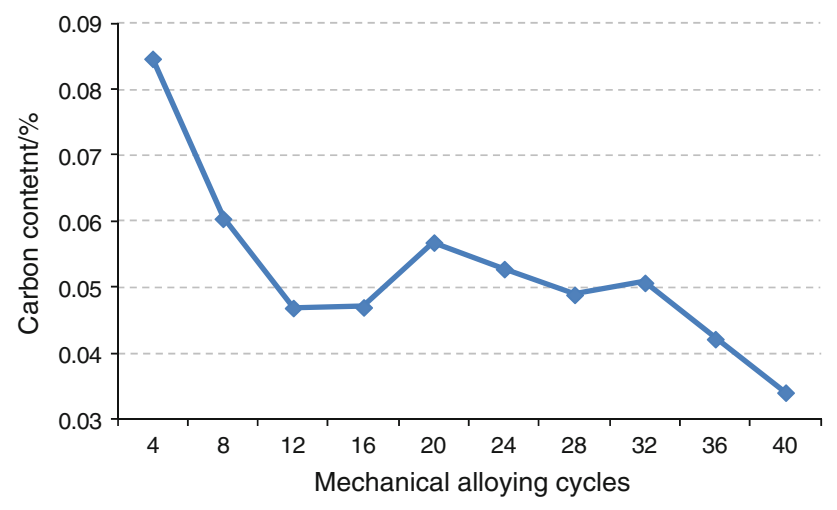

Fig. 11 Evolution of the carbon content of the investigated samples determined after heating to $1,200{ }^{\circ} \mathrm{C}$ versus the mechanical alloying cycles (milling time). (Color figure online)

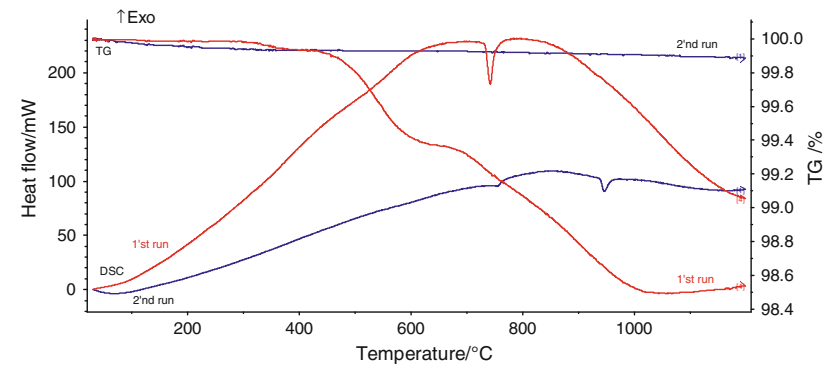

Fig. 12 DSC and TG curves of the Astaloy CrM powder with the addition of $1 \mathrm{wt} \%$ stearic acid after 40 mechanical alloying cycles (milling time) recorded upon heating the samples up to $1,200{ }^{\circ} \mathrm{C}$ directly after processing and during the second run. (Color figure online)

of carbon was the result of the disintegration of chemical chain of stearic acid by the MA process). The dominant role of the reducing activity of carbon in the reduction processes during the increase of milling time was confirmed by the analysis of carbon content for samples after heating to $1,200{ }^{\circ} \mathrm{C}$ (Fig. 11).

Figure 12 presents the differences for the DSC and TG curves for the Astaloy CrM powder with the addition of $1 \mathrm{wt} \%$ stearic acid after 40 mechanical alloying cycles recorded between first and second runs. The TG curve record during second run was unchanged as a result of removal of the lubricants from the sample during the first heating process. Moreover, on the DSC curve recorded during second heating was observed separation of the magnetic transition (at the Curie temperature) from the $\alpha \rightarrow \gamma$ transformation, which previously overlapped as an effect of the MA process (Figs. 2, 3). This phenomenon may be connected with the recovery and recrystallisation effects. Intensity and position of endothermic peaks were similar to those of the based Astaloy CrM powder (Fig. 1).

\section{Conclusions}

Mechanical alloying and the addition of $1 \mathrm{wt} \%$ stearic acid had a strong influence on the investigated Astaloy CrM powder after different duration times. At the beginning of the MA processes (up to 12 cycles), significant changes of powder morphology and significant calorimetric effects corresponding to the presence of PCA occurred. When the milling time exceeded $96 \mathrm{~min}$, a drastic increase in microhardness and a decrease in particle size were detected. QMS measurements and mass loss (about 1\%) recorded on the TG indicated that up to 16 cycles of the MA processing, gaseous products from stearic acid were hydrocarbon products and methyl group. However, when the time of the milling increased, the stearic acid probably disintegrated due to the high ball energy and temperature. This effect, most likely by an increase of the hydrogen product, helps the reduction process to occur in the milled samples. This explanation is confirmed by an increase in the masses of water, carbon monoxide and dioxide as well as a $1.5 \%$ mass loss observed on the TG curve, especially for samples after 36 and 40 cycles.

Acknowledgements The study was supported by the Polish Ministry of Science and Higher Education within grant No N N508 393237.

Open Access This article is distributed under the terms of the Creative Commons Attribution Noncommercial License which permits any noncommercial use, distribution, and reproduction in any medium, provided the original author(s) and source are credited.

\section{References}

1. El-Eskandarany MS. Mechanical alloying for fabrication of advanced engineering materials. Norwich, New York: William Andrew Publishing; 2001.

2. Restivo TAG, Mello-Castanho SRH. Sintering studies on $\mathrm{Ni}-\mathrm{Cu}-$ YSZ SOFC anode cermet processed by mechanical alloying. J Therm Anal Calorim. 2009;97:775-80.

3. Suryanarayana C, Ivanov E, Boldyrev VV. The science and technology of mechanical alloying. Mater Sci Eng A. 2001;304-306:151-8.

4. Baum MM, Becker RM, Lappas AM, Moss JA, Apelian D, Saha D, Kapinus VA. Lubricant pyrolysis during sintering of powder metallurgy compacts. Met Mater Trans B. 2004;35B:381-92.

5. Shaw L, Luo H, Villegas J, Miracle D. Compressive behavior of an extruded nanocrystalline Al-Fe-Cr-Ti alloy. Scripta Mater. 2004; 50:921-5.

6. Neamtu BV, Isnard O, Chicinas I, Vagner C, Jumate N, Plaindoux $\mathrm{P}$. Influence of benzene on the Ni3Fe nanocrystalline compound formation by wet mechanical alloying: An investigation combining DSC, X-ray diffraction, mass and IR spectrometries. Mater Chem Phys. 2011;125:364-9. 